\title{
All Rights Reversed: A Study Of Copyleft, Open-Source, And Open-Content Licensing
}

Dean A. Frantsvog, J.D., Minot State University, USA

If nature has made any one thing less susceptible than all others of exclusive property, it is the action of the thinking power called an idea, which an individual may exclusively possess as long as he keeps it to himself; but the moment it is divulged, it forces itself into the possession of every one, and the receiver cannot dispossess himself of it. Thomas Jefferson

Keywords: Law; Copyright; Open-Source; Copyleft

\section{INTRODUCTION}

$\mathrm{n}$ the United States and much of the world, the current framework of intellectual property laws revolves around protecting others from tampering with an author's work - the copyright holder decides who can use it, who can change it, and who can share. There is a growing school of thought, though, that holds that intellectual creations should be open to everyone to use, to modify, and to redistribute as they see fit, and take legal steps to ensure that others have the right and the opportunity to do so.

This idea, the general practice of using modern intellectual property laws to ensure that others will have the right to change one's work is known as "copyleft." The term "copyleft", a play on "copyright", is a way of legally ensuring that a work can be freely distributed or modified by anyone. Larry Lessig and Jonathan Zittran, two Harvard law professors and copyleft activists, claim that copyright laws have come to be a detrimental force, diminishing creativity instead of encouraging it. The copyleft movement, they claim is about rebalancing intellectual property laws to a purer, more Jeffersonian state. (Stim 230)

The difference between copyleft and copyright lies in the rights of the copyright holder. A work under copyright generally uses the disclaimer "all rights reserved." These rights, namely distributing, performing, and modifying the work, belong solely to the copyright holder (Goldstein 10). Under a copyleft license, the work is still under copyright, but the author gives up most or all of these rights. Copylefted works often bear the slogans "All rights reversed", "No rights reserved", or "Some rights reserved", depending on the specific terms of the license in use.

In other words, a work under a copyleft license is legally protected, and part of that protection is that it must always be free to use, distribute, and modify.

The use of copyleft licensing began with computer hobbyists in the mid-1970's, seeking to protect their programs from commercial use. Since then, the use of copyleft licensing has expanded; there are now licenses designed to protect text documents, images, songs, and other works. Today, some of the most notable users of copyleft licenses include Wikipedia (Wikipedia Contributors, "Wikipedia: Copyrights"), Creative Commons (Stim 240), the online creative works repository (founded by Lawrence Lessig), and the Mozilla Foundation, publisher of the Firefox internet browser (Behlendorf 166).

This paper will explore the history of copyleft licensing, some of the specific copyleft licenses in use, and two of the most pertinent trends branching from the movement: open-source licensing, and open-content licensing. 


\section{INTELLECTUAL PROPERTY: A BRIEF REFRESHER}

Intellectual property, IP, can be broken down into the three categories of copyrights, patents, and trademarks and servicemarks. Each is separate from the others and governed by their own structure of laws - despite being grouped together, patent laws have no say over copyrighted work, and vice versa. Each country has its own system of intellectual property, but the general principles are usually the same. (Circular One: Copyright Basics)

Copyrighting a work protects one's authorship of original works in a tangible medium. Among other mediums, the creator ("author") of a literary, musical, dramatic, pictorial, graphic, motion picture, sound recording, or architectural work has the right to copyright their work. (USC Title 17, Section 102)

The holder of a copyright has the exclusive right to reproduce and distribute the work, or authorize others to do so, prepare derivative works based upon the copyrighted work, and display or perform it publically. (Circular One: Copyright Basics)

Under copyright law, brief portions of a copyrighted work may be reproduced and distributed for a number of purposes, mainly providing criticism and commentary, news reporting, education, or research. This is known as fair use. (USC Title 17, Section 107) A work that is no longer under copyright, or one that failed to qualify for copyright protect, is considered to be in the public domain, meaning that it can be used by the public indiscriminately. (Stim 301)

A patent is granted by the United States Patent and Trademark Office to protect an invention; specifically, it is the right to "exclude others from making, using, offering for sale, or selling the invention throughout the United States or importing in the invention into the United States," but not the right itself to do these things. A patent usually expires twenty years after it is issued. (USC Title 35, Section 154) There is currently no analogue of copyleft licensing that applies to patent laws.

Grouped together are trademarks and servicemarks. A trademark is something that is used to identify a company's product, and distinguish it from competing products. A trademark can be a name or group of words, or a specific image, logo or design. A servicemark is the same as a trademark, except that it is used to denote a service, instead of a good. Trademarks and servicemarks are usually referred to collectively as trademarks, or simply as marks. (Stim 378)

\section{HISTORY OF COPYLEFT LICENSING}

The term "copyleft" first appeared in "Dr. Dobb's Journal", a monthly computer programming journal, in 1976. Part of the code for a computer program intended for free use, the text of the license read in part "C Copyleft; All Wrongs Reversed." (In modern copyleft works, the c-in-a-circle symbol is often mirrored, with the c backwards. While clever, it has no legal meaning on its own.)

At first, copyleft licensing only applied to computer software and code. This branch of the movement is now known today as the "free software movement." (Stallman 53)

The first modern copyleft license was developed in 1984 by Richard Stallman, a computer programmer. Stallman had given a public domain version of a computer program he developed to Symbolics, a now-defunct computer manufacturer. When Stallman asked to use their new, modified version of the program, the company refused. They had all legal right to, since Stallman, by placing the program in the public domain, had yielded all control over it. (Williams 7)

Because of this incident, Stallman created the Emacs General Public License. Named for the "Emacs" text editor program it was released with the, the license read in part

"GNU Emacs is free; this means that everyone is free to use it and free to redistribute it on a free basis. GNU Emacs is not in the public domain; it is copyrighted and there are restrictions on its distribution, but these 
restrictions are designed to permit everything that a good cooperating citizen would want to do. What is not allowed is to try to prevent others from further sharing any version of GNU Emacs that they might get from you... ...To make sure that everyone has such rights, we have to forbid you to deprive anyone else of these rights. For example, if you distribute copies of Emacs, you must give the recipients all the rights that you have. You must make sure that they, too, receive or can get the source code. And you must tell them their rights." (Emacs General Public License)

Though the Emacs license has long been outmoded, almost all mainstream copyleft licenses echo the rules it laid down, and the tone it set.

In 1985, Stallman became the founding president of the Free Software Foundation. The Foundation's first project was developing the GNU (pronounced 'gnu) Operating System, a completely free computer operating system. Today, the Foundation remains one of the largest and most active advocates for the free software movement. (Stallman 60)

The Foundation is responsible for the most widely-used free software license, the GNU General Public License (GNU GPL), a direct descendant of the Emacs General Public License. The GNU GPL still holds the "share and share alike" principle the Emacs license put forth, but it also contains terms governing derivative works, libraries and compiled works, and other areas. (Mustonen 9)

\section{LEGAL ELEMENTS OF COPYLEFT LICENSES}

Copyleft licensing isn't very different from a traditional copyright. Both aim to protect the ability to copy, modify, and distribute a work. The difference lies in who receives those rights. Under a copyright license, the author is the one being protected. Under a copyleft license, the object is to place those rights in the hands of the public. (Stallman 59)

It is important to note that while the public holds these rights, the work is not in the public domain. It is still protected by a copyright, just like any traditionally copyrighted work. This distinction can be confusing, since the average copyleft license has a fair amount in common with being in the public domain - both can be used, changed, or redistributed by anyone. However, a work in the public domain can be taken and used for profit - an example would be selling DVD's of The Beverly Hillbillies, a television program that has episodes in the public domain. A work protected by a copyleft license cannot be used for profit, as the license stipulates it cannot be sold, only freely distributed.

Most copyleft licensing share several common elements, including terms governing distribution, derived and modified works, attribution, and termination of the license.

In free software licenses, the text usually revolves around the source code, the computer language that defines the program. Aside from source code, the GNU GPL also requires that any additional libraries of information necessary to properly run the program, are included along with the source code. The output of running a program, any information that was generated during its use, is usually considered to be protected by copyleft as well. (GNU General Public License)

Since other copylefted material, such as art, doesn't have a "source code", these licenses naturally do not contain any terms governing it. No matter what the material, though, copyleft licenses always include a clause about distribution. The license grants the right to freely distribute an original copy of the work, or a modified copy of the work. (Free Art License)

Some licenses (the GNU GPL) allow the distributor to sell the copy if they choose, others mandate that a copy must not be charged for. (Mozilla Public License).

Certain licenses state that both modified and unmodified copies must also be protected under the same or under a similar license. These licenses are known as "strong licenses" within the copyleft community, an example being the GNU General Public License. (GNU General Public License) Conversely, licenses that do not require 
modified works to be similarly protected are dubbed "weak" licenses. The Common Public License, developed by IBM, is a good example of a weak license, as it only governs the use of the software, but not modification or redistribution. (Common Public License)

Another better-known weak license is the European Union Public License, developed by the European Commission, the executive organ of the European Union. It is classified as such because its terms allow for derivative works to be published under any license. (European Union Public License)

Advocacy groups such as the Free Software Foundation heavily favor strong licenses as they are selfperpetuating; by requiring all derived and modified works to use the same license, a single original work can spawn a large "family" of related works. In this respect, strong licenses are sometimes known as "viral" licenses (Mundie).

Copyleft licenses also usually allow a work to be freely incorporated into another work, as long as that work is also placed under a copyleft license. Some licenses require that when this occurs, the work must still be accessible on its own (such as the Free Art License), other do not (the GNU General Public License). Regardless, almost all licenses require attribution, acknowledging that a different author was responsible for creating that portion of the work.

Most copyleft licenses in circulation also have a very clear termination clause. The standard practice is that when a work is used in such a way it breaks the terms of the license, or a new license is attached to it or a modified work that violates the terms of the copyleft license previously in use, the license in considered termination. Sublicensing, or granting specific rights to a specific group or individual, is often prohibited as well (GNU General Public License).

\section{TRANSMISSION OF COPYLEFT PRACTICES FROM SOFTWARE TO OTHER MEDIUMS}

Though copyleft licensing is still most popular with computer software, it has slowly spread to be used in other mediums as well.

In 2000, the Free Art License was published by Copyleft Attitude, a French copyleft advocacy group. It is specifically intended for visual, sculptural, musical, or performance works. (Free Art License)

Like other copyleft licenses, the Free Art License grants the freedom to copy a work, distribute or perform it, modify it, or incorporate it into another work. If it is incorporated into a work in such a manner that it cannot be accessed independently, then that work must be licensed as copyleft as well, either under the Free Art License or another license. (Free Art License)

The text of the license has a libertarian, somewhat anti-establishment feel to it. The preamble reads:

While the public's access to creations of the human mind usually is restricted by the implementation of copyright law, it is favoured by the Free Art License. This license intends to allow the use of a work's resources; to establish new conditions for creating in order to increase creation opportunities. The Free Art License grants the right to use a work, and acknowledges the right holder's and the user's rights and responsibility... The main rationale for this Free Art License is to promote and protect these creations of the human mind according to the principles of copyleft: freedom to use, copy, distribute, transform, and prohibition of exclusive appropriation. (Free Art License)

The Free Art License has become the premier method to copyleft music, images, or other artistic works. There are multiple libraries of music online that have all been placed under copyleft license by their authors, such as socialbrite.org, opsound.org, and copyleft-music.com. Most of these utilize the Free Art License.

There are also copyleft licenses specifically designed for written documents. Of these, the foremost in use today is the GNU Free Documentation License, developed by the Free Software Foundation. 
The Free Documentation License was developed to provide a way to copyleft manuals, textbooks, encyclopedias, and other "functional" documents. Being similar in scope to the GNU General Public License, this license has terms governing copying and distribution material, translations of documents, collections of documents, and combining documents with independent works. (GNU Free Documentation License)

\section{THE MOTIVATIONS BEHIND THE COPYLEFT MOVEMENT}

While the technical aspects of copyleft licensing are clear and easy to understand, the motivations behind the movement are murky at best. What drives an individual to spend thousands of hours creating a work - a computer program, an artistic work, a translation of a document, and then willingly give away the rights to it?

It is the opinion of the author that at the heart of the copyleft movement is a strong disdain for modern forprofit intellectual property practices. The preamble to the GNU General Public License states that "The licenses for most software and other practical works are designed to take away your freedom to share and change the works. By contrast, the GNU General Public License is intended to guarantee your freedom to share and change all versions of a program--to make sure it remains free software for all its users..." (GNU General Public License)

According to the Free Software Foundation, the Intellectual Property system is "broken" and needs to be done away with. In an article on the Foundation's website, founder Richard Stallman puts forth that:

"It has become fashionable to toss copyright, patents, and trademarks - three separate and different entities involving three separate and different sets of laws-plus a dozen other laws into one pot and call it "intellectual property". The distorting and confusing term did not become common by accident. Companies that gain from the confusion promoted it. The clearest way out of the confusion is to reject the term entirely....

...The term carries a bias that is not hard to see: it suggests thinking about copyright, patents and trademarks by analogy with property rights for physical objects. (This analogy is at odds with the legal philosophies of copyright law, of patent law, and of trademark law, but only specialists know that.) These laws are in fact not much like physical property law, but use of this term leads legislators to change them to be more so. Since that is the change desired by the companies that exercise copyright, patent and trademark powers, the bias introduced by the term "intellectual property" suits them." (http://www.gnu.org/philosophy/not-ipr.html)

As discussed above, the heritage of copyleft lies in the hacker counterculture of the 1970's. It is steeped in a craving for intellectual freedom - sharing information openly, building on one another's work, and a playful aversion to authority. (This playfulness is evident in the fact that the entire name of the movement is a play on words.)

Over time, the mainstream copyleft movement seems to have lost its sense of anti-establishmentarianism, and is now centered on preserving the right to share one's own, and use other people's, ideas. It is a culture of sharing, using, reusing, and repurposing intellectual creations into new and useful forms.

\section{OPEN SOURCE LICENSING}

Open source licensing is a close relative of free software, differing on only a few key points. Open source is, in effect, a more corporatized version of free software, designed to be more functional in a business environment. (Perens 171)

The term "open source" was coined by the Open Source Initiative, a group formed in 1998 by Bruce Perens and Eric S. Raymond, two computer programmers. The group was also the first to publish a formal definition of open source licensing, written by Perens. (Perens 172) The 10-point definition stresses that for a license to be considered "open source", it "shall not restrict any party from selling or giving away the software", it "must allow modifications and derived works, and allow them to be distributed under the same terms as the license of the original software," that the license in use must not be specific to the product, and that "the license must not place restrictions on other software that is distributed along with the licensed software." (Open Source Definition) 
One the whole, open source licenses are much less strict than free licenses, and grant the author much more control over the work, keeping rights they normally would cede under a free software license. For example, open source software can work in conjunction with proprietary software, free software cannot. (Open Source Definition)

In 2008, a report published by the Boston-based technology research firm the Standish Group estimated that open-source software has saved consumers approximately \$US 60 billion per year (or, on the converse, decreased revenues for software firms by $\$$ US 60 billion per year). Whether this is good or bad, one must admit that open source software is a significant force in the market. (Standish Group)

A healthy example of an open source software project is the Firefox Internet browser. Developed by the Mozilla Foundation, a nonprofit formed in 2003, Firefox is licensed under the Mozilla Public License. As of March 2011, Mozilla was estimated to be the $2^{\text {nd }}$-most popular Internet browser, controlling $30 \%$ of the usage share. (Microsoft's Internet Explorer is estimated to control 45\%) (StatCount Global Stats)

\section{OPEN CONTENT LICENSING}

A blend between open source licensing and copyleft licensing is open content - it focuses more on allowing others to use and share material, but not necessarily the rights to modify and redistribute it.

Creative Commons is not pure copyleft, but instead touts a "reasonable flexibility." It has received large donations from Google, the Mozilla Foundation, Best Buy, Ebay, Nike, and Microsoft, among other organizations. (Creative Commons, "Supporters")

Founded in 2011, Creative Commons has developed a number of licenses that allows authors to pick and choose which rights they wish to hold. The structure revolves around the right to attribution, restriction to noncommercial purposes, restriction of derivative works, and what the organizations terms as "share-like", the stipulation that any derivative work is released under the same license as the original. Authors, when adding a work to Creative Commons, choose which license they wish to use, based on which of the four terms they wish to include. Because of this, Creative Commons licenses bear the text "Some Rights Reserved". (Creative Commons, "Before Licensing")

The organization maintains a number of directories dedicated to cataloguing works released under its licenses. It has separate databases for music, images, maps, video works, audio clips, and other mediums.

The largest open content project in existence today is Wikipedia. The Internet encyclopedia has been translated into 282 different languages (WikiMedia Foundation); as of July 2011, the English version contained over 3,686,000 articles, all of which is licensed under the Creative Commons Attribution/Share-alike license (Wikipedia contributors, "Wikipedia:Copyrights").

\section{CONCLUSION}

It is simply staggering to think of the countless man-hours that are poured into copyleft, open source and open content projects, all for no more than a sense of contribution to the intellectual whole.

For one who is used to a strictly commercial environment, it can be mind-boggling to try to understand what motivates the authors who license their materials under copyleft protection. Indeed, there are some who claim that with no valid commercial application, the copyleft movement is sure to fail. However, the growing availability of copyleft material clearly signals that the movement is not losing momentum.

It is the prediction of the author that the copyleft movement will continue to expand and grow in both scope and momentum. With the growing amount of material available, a copyleft textbook might be used in schools sometime in the near future. Firms such as iStockphoto might soon find themselves in serious jeopardy, because CreativeCommons or similar outfits can provide a more comprehensive database, for free. 
Even though such drastic changes may be a long way off, copyleft is changing the framework of intellectual property, and it is here to stay.

\section{AUTHOR INFORMATION}

Dean Frantsvog is an Associate Professor of Law in the College of Business at Minot State University, Minot, North Dakota. After receiving his Juris Doctorate degree from Hamline University School of Law, Mr. Frantsvog began his law practice in Minot, focusing primarily on small business, financial and regulatory matters. He began teaching at Minot State University in 2004, where he serves in the Accounting and Finance Department of the College of Business. In 2002, Mr. Frantsvog was elected to Minot's City Council, where he currently serves as President. E-mail: dean.frantsvog@minotstateu.edu.

\section{REFERENCES}

1. "Before Licensing." Creativecommons.org. Creative Commons, n.d., Web. 〈http://wiki.creativecommons.org/Before_Licensing >

2. $\quad$ Behlendorf, Brian. "Open Source as a Business Strategy." Open Sources: Voices from the Open Source Revolution. Ed. Chris DiBona, Sam Ockman, Mark Stone. Sebastopol, CA: O'Reilly \& Associates, Inc, 1999. Print.

3. $\quad$ "Common Public License." eclipse.org. Eclipse Foundation, 0416 2009. Web. <http://www.eclipse.org/legal/cpl-v10.html>.

4. "Emacs General Public License." free-soft.org. Free Software Foundation, n.d. Web. <http://www.freesoft.org/gpl_history/emacs_gpl.html>.

5. $\quad$ "European Union Public License." EUPL v.1.1. European Commission, n.d. Web. 10 Aug 2011. 〈http://www.osor.eu/eupl/eupl-v1.1/en/EUPL\%20v.1.1\%20-\%20Preamble.pdf〉.

6. $\quad$ "Free Art License 1.3." artlibre.org. Copyleft Attitude, 2007. Web. <http://artlibre.org/licence/lal/en>.

7. $\quad$ "GNU Free Documentation License." gnu.org. Free Software Foundation, 11 2008. Web. 〈http://www.gnu.org/licenses/fdl.html>.

8. $\quad$ "GNU General Public License." gnu.org. , 0629 2007. Web. <http://www.gnu.org/copyleft/gpl.html>.

9. Goldstein, Paul. Copyright's Highway: The Law and Lore of Copyright from Gutenberg to the Celestial Jukebox. 1st ed. New York: Hill and Wang, 1994. Print.

10. $\quad$ "List of Wikipedias." WikiMedia: MetaWiki. WikiMedia Foundation, 1407 2011. Web. $\langle$ http://meta.wikimedia.org/wiki/List_of_Wikipedias $>$.

11. Mundie, Craig. "The Commercial Software Model." New York University, New York, NY. 05032001. Speech.

12. Mustonen, Mikko. "Copyleft - the economics of Linux and other open source software." University of Helsinki, n.d. Web.

13. Perens, Bruce. "The Open Source Definition (Annotated)." opensource.org. Open Source Initiative, n.d. Web. 10 Aug 2011. <http://www.opensource.org/osd.html>.

14. $\quad$ Perens, Bruce. "The Open Source Definition." Open Sources: Voices from the Open Source Revolution. Ed. Chris DiBona, Sam Ockman, Mark Stone. Sebastopol, CA: O'Reilly \& Associates, Inc, 1999. Print.

15. Press release, standishgroup.com. The Standish Group, 0418 2008. Web. 〈http://standishgroup.com/newsroom/open_source.php〉.

16. Stallman, Richard. "Did You Say “Intellectual Property”? It's a Seductive Mirage." gnu.org. Free Software Foundation, n.d. Web. 〈http://www.gnu.org/philosophy/not-ipr.html〉.

17. Stallman, Richard. "The GNU Operating System and the Free Software Movement." Open Sources: Voices from the Open Source Revolution. Ed. Chris DiBona, Sam Ockman, Mark Stone. Sebastopol, CA: O'Reilly \& Associates, Inc, 1999. Print.

18. Stim, Richard. Patent, Copyright \& Trademark: An Intellectual Property Desk Reference. 11th ed. Berkeley, CA: Nolo, 2010. Print.

19. "Supporters." creativecommons.org. Creative Commons, n.d. Web. <http://gs.statcounter.com/\#browserww-monthly-201103-201103-bar>.

20. $\quad$ "Top 5 Browsers on Mar 11." StatCount GlobalStats. StatCount GlobalStates, n.d. Web. <http://gs.statcounter.com/\#browser-ww-monthly-201103-201103-bar>. 
21. U.S. Copyright Office Circular One: Copyright Basics. Washington, D.C.: U.S. Government Printing Office, 2010. Web. 9 Aug 2011. 〈http://www.copyright.gov/circs/circ01.pdf>.

22. Williams, Sam. Free as in Freedom: Richard Stallman's Crusade for Free Software. Sebastopol, CA: O'Reilly \& Associates, Inc, 2002. eBook.

23. Wikipedia Contributors. "Wikipedia:Copyrights." Wikipedia, The Free Encylopedia. Web. <http://en.wikipedia.org/wiki/Wikipedia:Copyrights>. 